\title{
Übersicht über die Arten der Gattung Boromorphus Woll. mit Ausschluß der Spezies von Madeira.
}

\author{
Von Edm. Reitter in Paskau (Mähren).
}

1" Flügeldecken auch an den Seiten ohne deutliche Längsfältchen oder Längskielchen auf den abwechselnden Zwischenräumen der Punktstreifen.

2" Halsschild viel länger als breit, weit vor der Mitte am breitesten, Flügeldecken nur doppelt so lang als der Thorax, mit dichten, feinen, weitläufig punktierten Punktreihen, die Zwischenräume derselben nicht feiner punktiert als die ersteren, Glied 4-8 der Fühler kaum länger als breit. Rostrot, der Scheitel und die Flügeldecken dunkelbraun. - S p a n i e n, A l g i er, M a r o k ko.

\section{tagenioides Luc.*)}

2' Halsschild kaum länger als breit, an den Seiten wenig gerundet, dicht vor der Vitte am breitesten, Flügeldecken beträchtlich' länger wie doppelt so lang als der Thorax, oben mit deutlichen dicht punktierten Punktstreifen, die schmalen Zwischenräume einzeln, feiner punktiert als die Hauptreihen, Fühler lang und dünn, Glied 4-8 viel länger als breit. Körper rotbraun. Araxestal. - D. 1889. 33.

armeniacus Reitt.**)

1' Flügeldecken wenigstens an den Seiten mit feinen Längsfalten oder Längskielchen auf den abwechs. Zwischenräumen der Punktstreifen.

3" Halsschild mindestens so lang als breit, Flügeldecken an den Seiten mit sehr schwachen Längsfalten, mehr wie doppelt so lang als zusammen breit, Fühler länger, Körper größer.

4" Fühler dünn und lang, Glied 4-8 länglich, Flügeldecken wie bei armeniacus punktiert, Körper braun, matt, Fühler und Beine gelbrot. Long. 3 bis $32 \mathrm{~mm}$. Transkaukasus, Talyschgebirge, Araxestal, Transkaspien, Turkestan.

opaculus Reitt.

4' Fühler kürzer, Glied 5-8 kaum länger als breit, Flügeldecken wie bei tagenioides punktiert, Körper rostrot, bis rotbraun, etwas glänzend. Long. 3 bis $2 \cdot 2 \mathrm{~mm}$. Kairo. aegyptiacus n. sp.

3' Halsschild merklich breiter als lang, Flügeldecken an den Seiten mit starken Längskielchen, höchstens doppelt so lang als zusammen breit; Fühler kurz, Glied $4-8$ kaum so lang als breit, Körper klein, rostrot, etwas glänzend. Long. 2 bis $2.3 \mathrm{~mm}$. Syrien.

libanicus Bandi.

*) $\mathrm{Ob}$ B. maderae Woll. hiezu als Synonym gehört, wie Marseul in seinem Katalog ausgewiesen hat, ist sehr zweifelhaft.

**) Ist vielleicht nur Rasse des opaculus Reitt.

Wiener Entomologische Zeitung, XXVII. Jahrg., Heft VI und VII (15. Juni 1903). 


\section{$2 \mathrm{BHL}$ Biodiversity Heritage Library}

Reitter, Edmund. 1908. "Übersicht über die Arten der Gattung Boromorphus WOLL. mit Ausschluß der Spezies von Madeira." Wiener entomologische Zeitung 27, 217. https://doi.org/10.5962/bhl.part.11626.

View This Item Online: https://www.biodiversitylibrary.org/item/43799

DOI: https://doi.org/10.5962/bhl.part.11626

Permalink: https://www.biodiversitylibrary.org/partpdf/11626

\section{Holding Institution}

Smithsonian Libraries

\section{Sponsored by}

Smithsonian

\section{Copyright \& Reuse}

Copyright Status: NOT_IN_COPYRIGHT

This document was created from content at the Biodiversity Heritage Library, the world's largest open access digital library for biodiversity literature and archives. Visit BHL at https://www.biodiversitylibrary.org. 